\title{
The Evaluation of Pharmaceutical Packaging Pictograms via Eye Tracking Technique
}

Merve Memişoğlu, $P h D^{1}$; Yener Girişken, $P h D^{2}$

${ }^{1}$ Department of Social Pharmacy, Faculty of Pharmacy, Biruni University, Istanbul, Turkey

${ }^{2}$ Department of Marketing, Faculty of Business Administration, Altınbaş University, Istanbul, Turkey

\begin{abstract}
Background: Various visual tools are used to improve medication adherence in communication with the patient. Pharmaceutical pictograms are one such tool utilized within this communication process.

Objective: The aim of this study is to investigate the eye movement of the participants and to recommend the most suitable location of pictograms on pharmaceutical packaging accordingly. It also aims to show whether there is a significant correlation between the effectiveness of pictograms and the health literacy, age, and gender of the participant.

Methods: Forty-two participants were exposed to sixty stimuli showing four different pharmaceutical packages as an on-screen slide show. Participants were asked what they understood from the pictograms on the packaging, and their eye movements were examined using eye tracking to determine heat maps and areas of interest, and to measure the time to first fixation, total fixation duration, and percentage fixated.

Results: The study revealed that the understanding level of the pictograms was determined at between $11.9 \%$ and $71.43 \%$. Among the pictograms, only a small percentage 13\% - namely numbers 12 and 13 which were prepared and validated by the FIP, achieved a score of $67 \%$, the minimum level of comprehension in accordance with ISO 3684. We observed that participants fixated at least once on the pictograms up to 95\% of the time. The pictograms were found to be most easily noticed at the center with a secondary focus area towards center-right parts of the packaging. Vertical design was highly engaging for participants regardless of health literacy. The significant relationship was found between the understanding of the pictograms and gender when mean values are examined. However, no significant relationship was between health literacy and pictogram comprehension level.

Conclusions: This is the first study to have used eye tracking to analyze pictograms added to real pharmaceutical packaging on the market. Its findings can guide pharmaceutical companies to design their packaging in a way that prioritizes patient safety, and to place critical pictograms more effectively. These results can be adapted medication label design in hospitals to promote appropriate use. Studies to improve patient adherence by using pictograms should be diversified.
\end{abstract}

Keywords: Pharmaceutical pictograms; Pharmaceutical labelling; Eye tracking; Patient safety; Medication adherence; Pharmaceutical marketing, Turkey

\section{INTRODUCTION}

Promoting medication adherence reduce healthcare costs ${ }^{1-2}$ and enhances patient safety ${ }^{3}$. Medication adherence can increase with the patient's comprehension of drug-related information and their safe use. In this context, a key consideration is how to improve the communication process with patients. Visual tools such as pictograms can provide effective communication. This is because graphic information is more effective than text ${ }^{4}$. In comparison to visually given instructions, patients more often fail to remember verbal instructions. The rate of such failure increases dramatically where patients are elderly or uneducated ${ }^{5-10}$. Understanding the complexity of pharmaceutical information leaflets, pictograms were introduced to ease and aid patients with reading difficulties. Yet some factors such as age, language, cultural groups, reading ability, hearing impairment and health literacy level have an impact on the correct comprehension and retention of pictograms ${ }^{11}$.

Corresponding author: Merve Memişoğlu, PhD

E-mail: mmerve.memisoglu@gmail.com https://orcid.org/0000-0002-8068-6836
Howard et al. reported that low health literacy causes several consequences such as increased health costs, difficulty in medical controls, and length of hospitalization ${ }^{12}$. One method of counteracting weak patient literacy is to replace written instructions with pictorial and audio-visual educational material ${ }^{13}$. Pharmaceutical pictograms are an effective tool that can be used to communicate medical information in a clear, fast and simple way ${ }^{9}$. Furthermore, Mansoor and Dowse showed that pictograms enable comprehension of complicated information ${ }^{14}$. While there are many studies on the impact of pictograms on various patient groups including different literacy levels, none used eye-tracking as a method, unlike our study ${ }^{11,15-16}$.

According to the International Standard for Safety Colors and Safety Signs, safety signs should have a comprehension rate of at least $67 \%$ (ISO 3864). For safety reasons, this ratio should be higher for pharmaceutical pictograms ${ }^{17}$. A study done by Van Beusekom et al. showed that only half of the pictograms reached the $67 \%$ comprehension rate. They found that pictograms were more effective for people who were familiar with their visual elements and messages. They also emphasized that implementers should focus on familiarity and simplicity for pictograms which show the method of intake and the effects of pharmaceutical products ${ }^{18}$. Similarly, Chan et al. reported that 
pharmaceutical pictograms should highlight connections and familiarity with user characteristics and reflect these within pictogram features ${ }^{19}$.

There are also legal regulations that apply to the use of pharmaceutical pictograms. According to Article 62 in Directive 2001/83/EC, "pictograms to aid comprehension of the information may appear on outer labeling as long as they are in line with the summary of product characteristics (SmPC) and are not promotional or misleading, and do not interfere with legibility"20. Similarly, US laws on packaging require all warnings and caution statements to be "conspicuous and prominent" 21 .

On the other hand, there are cases where some pictograms have not achieved the minimum comprehension rate among the patients, or else where the pictograms were inconsistent ${ }^{22-}$

${ }^{23}$. Studies suggest that early-stage involvement of all parties can solve many of the educational and/or communicational challenges. The design of such process must include the target population $^{24}$. The development of pharmaceutical pictograms is one of the key challenges within such a design process for improving medication adherence and requires special expertise in both pharmaceutical and communication sciences ${ }^{25-26}$.

In this context, the aim of this study is to investigate the eye movement (gaze) of the participants and to recommend the most suitable location of pictograms on pharmaceutical packaging accordingly. In a study conducted in Turkey in 2014, almost half of the population was shown to have limited health literacy ${ }^{27}$. This study also aims to show whether there is a significant correlation between the effectiveness of pictograms and the health literacy, age, and gender of the participant.

In some cases, pictograms alone may not be sufficient. Katz et al. showed that the pictograms are more effective when used with a simple description ${ }^{28}$. Therefore, in our study, pictograms with short descriptions were also shown to the participants and their response examined.

\section{METHODS}

\section{Participants}

The study was conducted in Istanbul, Turkey and performed in a NeuroLab, ThinkNeuro as a neuromarketing laboratory which is designed to provide interdisciplinary academic research and sector-specific projects led by Dr. Girişken.

Ethical approval was provided by Biruni University Ethical Committee (CSS ref: 2018-20-01).

After obtaining ethical approval, data collection took place between February 2019 and March 2019. The study sample consists of 42 healthy volunteers ( 21 males and 21 females) between the ages of 25-65.

Table 1. Characteristics of the sample population and products

\begin{tabular}{cccc}
\hline User Factor & Level & Number (n) & Percentage (\%) \\
\hline Gender & Male & 21 & 50 \\
& Female & 21 & 50 \\
\hline Age & $25-34$ & 8 & 19.05 \\
& $35-44$ & 13 & 30.95 \\
& $45-54$ & 12 & 28.57 \\
& $55-65$ & 9 & 21.43 \\
\hline Health Literacy & insufficient & 6 & 14.29 \\
& problematic & 15 & 35.71 \\
& sufficient & 16 & 38.10 \\
& excellent & 5 & 11.90 \\
\hline Product ID & Type of drugs & Active metabolites & Therapeutic groups \\
\hline Product 1 & $R x$ & Amoxicillin/Clavulanic acid & Antibiotics \\
Product 2 & $R x$ & Metformin hydrochloride & Antidiabetic \\
Product 3 & OTC & Hyoscine N-butyl bromide & Antispasmodic
\end{tabular}

The health literacy level of the participants was also measured in our study. The participants were classified according to age, gender, and health literacy level. In order to determine the health literacy level of the participants; the Turkish version of the European Health Literacy Scale (ASOY-TR) was used. The European Health Literacy Scale (HLS-EU-Q47) consists of 47 items across 12 subdomains. ASOY-TR, like HLS-EU, foresees four levels of health literacy; insufficient (0-25), problematic (>25-33), sufficient (>33-42) and excellent (>42-50).

\section{Pictograms}

Packaging is the primary source of information and its design gives consumers an idea as to the quality of products and thereby affects consumer brand perception. The importance of warnings on packaging is essential for public health. Therefore, it is critical to give such warnings clearly. For this purpose, in our study, drug-related warnings were shown as pictograms on the packaging and their effectiveness measured. 
In this study, we examined pharmaceutical pictograms and their placement on packaging (right and left) via survey and eye tracking. The noticeability of the pictograms was evaluated by 42 Turkish participants using 4 different pharmaceutical packages, which were selected randomly from the market. Each sample had a different therapeutic effect and was divided into the two categories of prescription drugs $(\mathrm{Rx})$ and nonprescription drugs (OTC). Pictograms were chosen and created based on the warnings and safety information in the package inserts of the related drugs. In this context, USP, FIP pictograms and new pharmaceutical pictograms in accordance with the Summary of Product Characteristics (SmPC) were used.

A slideshow of the 13 pictograms was presented to participants, who were asked to write the meaning of each pictogram. The intended meaning of each pictogram was then presented to the participants and the results compared. The photos of pharmaceutical packages with pictograms were also shown to the participants via the screen. Forty-two participants were exposed to sixty stimuli showing four different pharmaceutical packages as an on-screen slide show.

In this article, company logos and brand names on the packaging were blurred because of using real pharmaceutical products.

These pictograms which were similar size were later placed on pharmaceutical package samples.

Within each sample, areas of interest (AOI) were defined for eye tracking. The AOIs were larger than the target pictures to compensate for the inaccuracy of human vision.

Although United States Pharmacopeia (USP) and International Pharmacy Federation (FIP) developed various pictograms, they require modifications based on the region that they will be used in. For this reason, in addition to the pictograms of the USP and FIP, new pharmaceutical pictograms were also used in our study.

Four different types of pictograms were used: i) 4 USP pictograms, ii) 5 FIP pictograms, iii) 1 from a reference article by van Beusekom et al. ${ }^{18}$, and iv) 3 local pictograms modified according to related Summary of Product Characteristics.

\section{Eye Tracking}

Meeting quality criteria such as objectivity, reliability and validity in questionnaires can sometimes be difficult. For this reason, in our study we analyzed participants' responses as well as their visual attention and gaze behavior using eye tracking techniques.
Eye tracking provides the most detailed information on consumers' visual attention. Fixation analyzes are important to understand whether participants are looking at a certain point on a certain stimulus. How many of the participants? which section? for how long? It helps us to understand the effects of these parts, as it can be determined that they pay attention to them.

To detect eye movement of participants, Tobii X120 which is the most known eye-tracker, was used. The device tracks the pupilla with a sensitive mechanism to produce quantitative results. During a recording, eye tracker collects raw eye movement data points every 3.3 to $33 \mathrm{~ms}$.

The study uses four different packages relating to different therapeutic groups. The packaging material was shown to the participants and remained on-screen for 5 seconds. At this point, the know-how and experience of the laboratory where the research was carried out was used for the 5-second demonstration. In previous similar non-academic studies, it was concluded that 5 seconds is both short enough for the participants to focus on the stimuli they see on the screen and long enough to not allow the data to be manipulated.

During this phase, the participants' eye movements were measured and mapped. After the eye tracking measurements, the data gathered was analyzed and the average gaze plot of all 42 participants was reported as heat map results. A heat map uses different colors to show the number of fixations participants made in certain areas of the image or for how long they fixated within that area. Red usually indicates the highest number of fixations or the longest time, and green the least, with varying levels in between.

In general, via eye tracking, the cognitive processes covering visual experience such as; attention, preference, are able to be studied. Eye tracking technology is performed in a broad variety of research fields, from neuroscience to psychology.

\section{Statistical analysis}

The statistical analysis of the results was performed with Students' $t$-test, non-parametric ANOVA tests, and Pearson linear correlations.

\section{RESULTS}

In this study, the understanding level of the pictograms was determined at between $11.9 \%$ and $71.43 \%$. Among the pictograms, only a small percentage $13 \%$ - namely numbers 12 and 13 achieved a score of $67 \%$, the minimum level of comprehension in accordance with ISO 3684. Both of the aforementioned appropriate pictograms were prepared and validated by the FIP. 
Table 2. Pharmaceutical pictograms and percentage of participants' comprehension

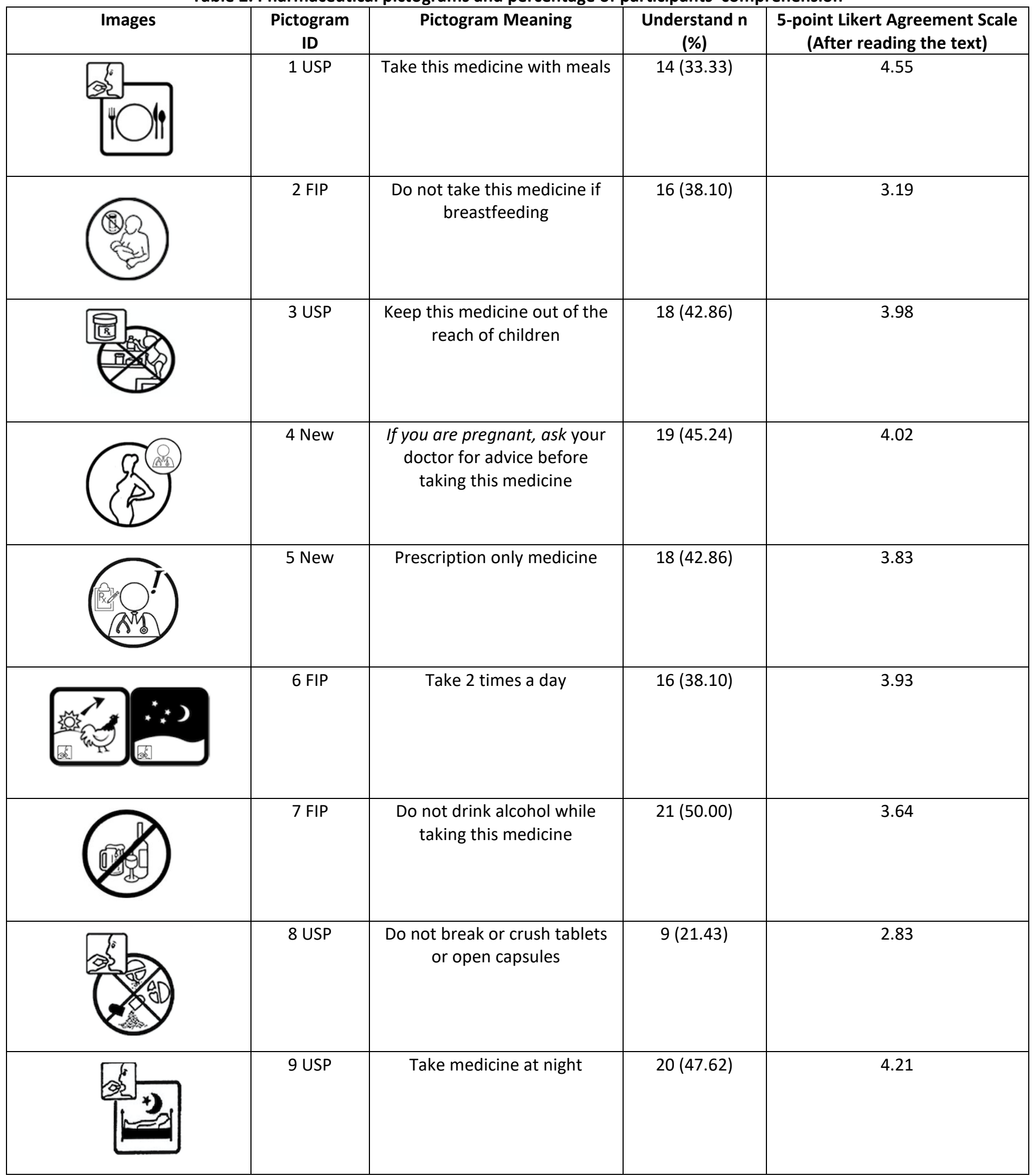




\begin{tabular}{|l|c|c|c|c|}
\hline & 10 New & $\begin{array}{c}\text { Do not take this medicine } \\
\text { continuously for more than } 7 \\
\text { days }\end{array}$ & 15 (35.71) & 3.86 \\
\hline & $\begin{array}{c}11 \text { (Van } \\
\text { Beusekom } \\
\text { et al., } \\
\left.2017^{18}\right)\end{array}$ & $\begin{array}{r}\text { Do not store warmer than } \\
30^{\circ} \mathrm{C}\end{array}$ & 5 (11.9) & 3.12 \\
\hline
\end{tabular}

It was found that the eye movement (gaze) of participants changed depending on the position of the visuals. The results showed that pictogram noticeability varied with the placement on the packaging. Accordingly, the pictograms were found to be most easily noticed at the center (Figure 1 and 2).
The heat map visualizes the gaze behavior of participants as hot and cold spots on the packages. As shown in Figure 1, older people are more focused on the brand name and the active substance rather than pictograms. In addition, younger participants had dispersed visual targeting, which leads to the conclusion that timing and prioritization of fixation should be analyzed.
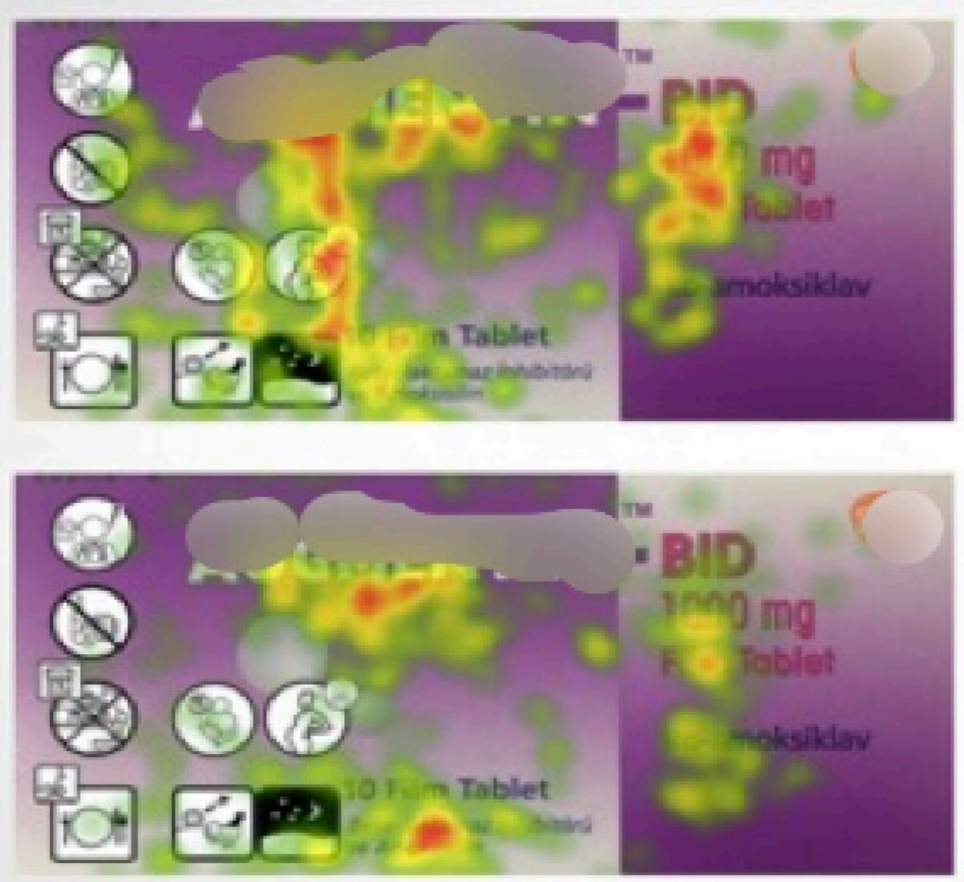

Figure 1. Heat map with fixation marks of Product 1 for different age groups 
Table 3. Time to first fixation, Total fixation duration mean, Percentage fixated Time to first fixation

\begin{tabular}{|c|c|c|c|c|}
\hline & Product 1 & Product 2 & Product 3 & Product 4 \\
\hline Female & $1.72 \pm 1.35$ & $1.96 \pm 1.38$ & $2.40 \pm 1.51$ & $1.74 \pm 1.27$ \\
\hline Male & $1.07 \pm 1.10$ & $3.02 \pm 1.43$ & $2.33 \pm 1.34$ & $1.82 \pm 1.20$ \\
\hline Adequately literate & $1.06 \pm 0.93$ & $1.72 \pm 1.29$ & $2.16 \pm 1.34$ & $1.52 \pm 1.06$ \\
\hline Low literate & $1.74 \pm 1.47$ & $3.02 \pm 1.38$ & $2.69 \pm 1.57$ & $2.04 \pm 1.32$ \\
\hline Age: $25-44$ & $1.19 \pm 0.96$ & $2.61 \pm 1.31$ & $2.87 \pm 1.27$ & $1.69 \pm 1.26$ \\
\hline Age: 45-65 & $1.65 \pm 1.58$ & $2.22 \pm 1.59$ & $1.67 \pm 1.40$ & $1.86 \pm 1.67$ \\
\hline \multicolumn{5}{|c|}{ Total fixation duration mean } \\
\hline & Product 1 & Product 2 & Product 3 & Product 4 \\
\hline Female & $1.24 \pm 1.09$ & $1.26 \pm 1.24$ & $0.93 \pm 0.75$ & $0.87 \pm 0.78$ \\
\hline Male & $0.90 \pm 0.90$ & $1.05 \pm 1.08$ & $0.61 \pm 0.48$ & $1.16 \pm 0.89$ \\
\hline Adequately literate & $1.02 \pm 1.12$ & $1.32 \pm 1.45$ & $0.88 \pm 0.69$ & $1.12 \pm 1.04$ \\
\hline Low literate & $1.12 \pm 0.87$ & $1.03 \pm 0.82$ & $0.77 \pm 0.72$ & $0.92 \pm 0.58$ \\
\hline Age: $25-44$ & $1.00 \pm 0.91$ & $1.48 \pm 1.13$ & $0.63 \pm 0.57$ & $0.96 \pm 0.95$ \\
\hline Age: 45-65 & $1.17 \pm 1.14$ & $0.99 \pm 1.18$ & $1.13 \pm 0.76$ & $1.06 \pm 0.74$ \\
\hline \multicolumn{5}{|l|}{ Percentage fixated } \\
\hline & Product 1 & Product 2 & Product 3 & Product 4 \\
\hline Female & $71 \% \pm 0.46$ & $52 \% \pm 0.51$ & $57 \% \pm 0.51$ & $90 \% \pm 0.30$ \\
\hline Male & $76 \% \pm 0.44$ & $33 \% \pm 0.48$ & $24 \% \pm 0.44$ & $90 \% \pm 0.30$ \\
\hline Adequately literate & $76 \% \pm 0.44$ & $43 \% \pm 0.51$ & $48 \% \pm 0.51$ & $90 \% \pm 0.30$ \\
\hline Low literate & $71 \% \pm 0.46$ & $43 \% \pm 0.51$ & $33 \% \pm 0.48$ & $90 \% \pm 0.30$ \\
\hline Age: $25-44$ & $86 \% \pm 0.36$ & $33 \% \pm 0.48$ & $48 \% \pm 0.51$ & $86 \% \pm 0.36$ \\
\hline Age: 45-65 & $62 \% \pm 0.50$ & $52 \% \pm 0.51$ & $33 \% \pm 0.48$ & $95 \% \pm 0.22$ \\
\hline
\end{tabular}

"Time to First Fixation" is necessary to measure how quickly the different AOls were seen in seconds. Time to first fixation was carried out using four products and across different demographics.

The findings, as relayed in Table 3, clearly show the time to first fixation is faster for adequately literate participants compared to participants with low literacy. Regarding product 1, male participants have shown faster fixation than females. Conversely, the fixations of female participants were faster than those of males for product 2. Younger participants demonstrated faster fixation times than older participants. Regarding products 2 and 3, it was seen that older participants fixated to pictograms faster than younger participants. This result is consistent with the other findings of our study in that it indicates that noticeability is related to the location of the pictograms (Figure 5). Pictograms are located on the left side of the packaging for product 1 , and on the right side for products 2 and 3.
Table 3 also includes comparable fixation times among 4 different products. The results reveal female participants focus more on pictograms than male participants except product 4 . Similarly, participants of adequate literacy focus more on pictograms than low-literate participants except for product 1. Elderly participants also focus more on pictograms than young participants except for product 2.

With the fixation percentage study, we attempted to measure the percentage of participants that have fixated at least once within an AOI. Participants were able to fixate at least once within pictograms for all product samples, though varying among different products, from $24 \%$ to $95 \%$ of the time. The percentage fixation for Product 4 (Figure 2) is higher than other products (86-95\%) for all demographic characteristics. Product 1 follows in second place and has also higher percentage fixated like product 1 due to the positioning of some pictograms. We observed that high percentage fixation is achieved as a result of some of the pictograms being placed near the center of the packaging. Although the percentage of young people for product 1 (86\%) and the elderly for product 4 (95\%) had high percentage rates fixation, there was no remarkable difference in their time to first and total fixation durations. 


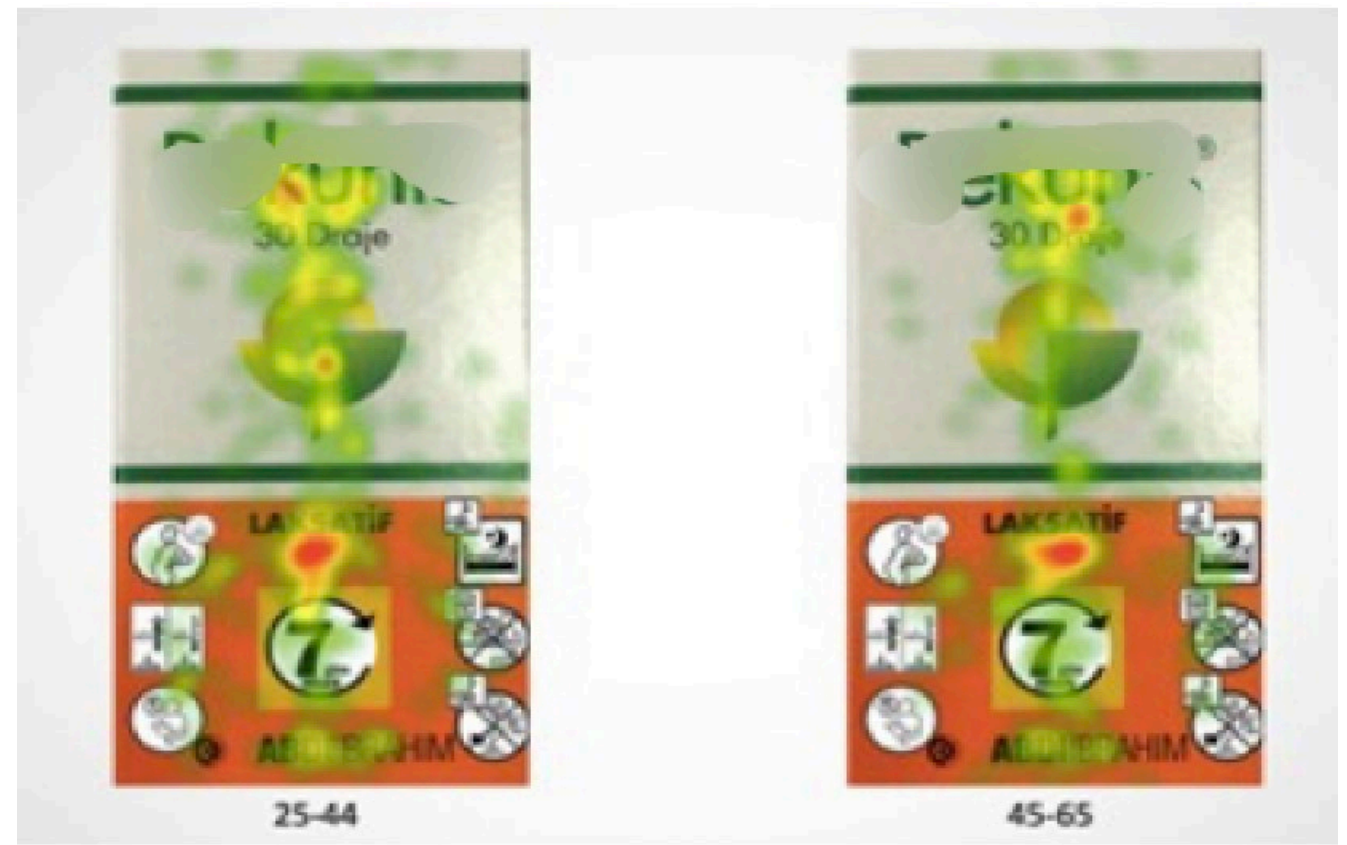

Figure 2. Heat map with fixation marks of Product 4 for different age groups

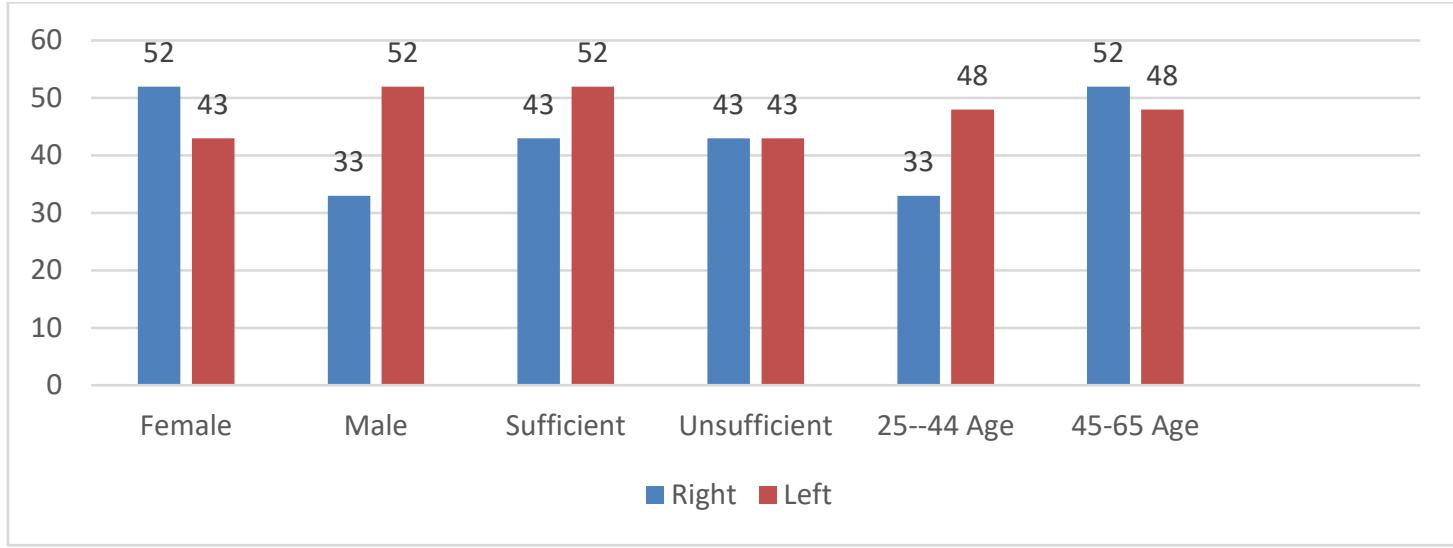

Figure 3. Percentage fixated of product 2 (right and left pictograms)

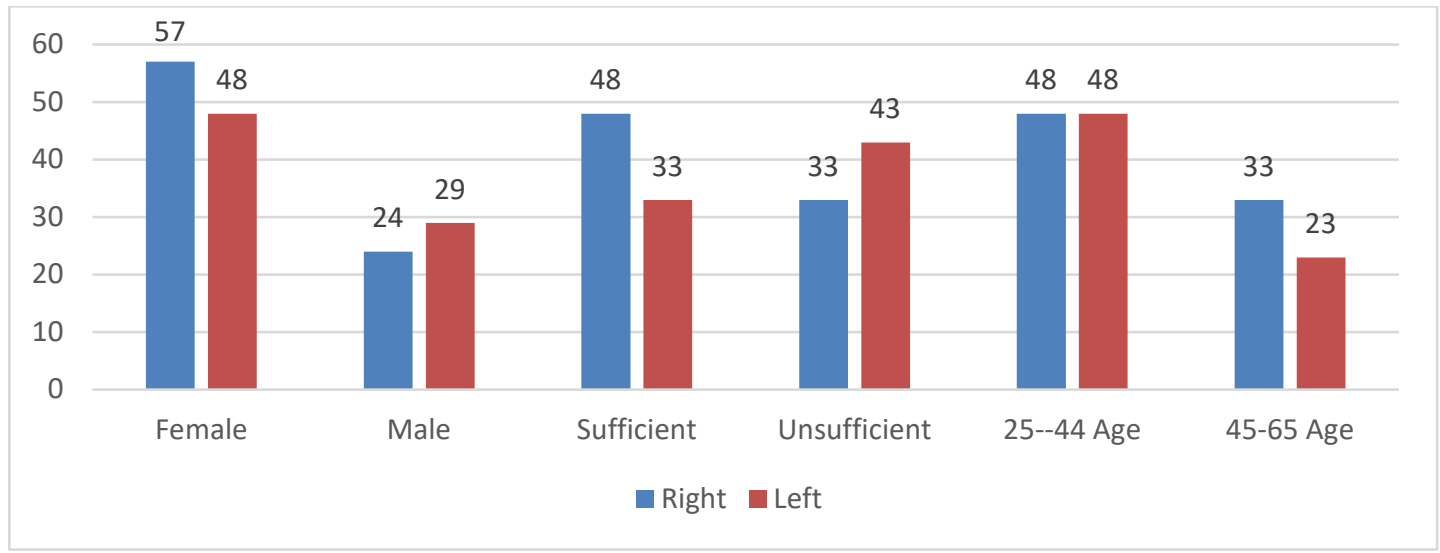

Figure 4. Percentage fixated of product 3 (right and left pictograms) 
The effect of placing the pictograms on the right and left sides of the package was also measured (Figure 5). As shown in Figures 3 and 4 , the pictograms attract female's attention when placed on the right side of the packaging and male's attention when placed on the left side. Similarly, it was found that the elderly paid attention to the pictogram on the right side, like females for all examples. For product 2, participants with adequate literacy paid attention to the pictogram on the left side like males. Conversely, for product 3 they paid attention to the pictogram on the right side like females. This result can be paralleled with relevant right-brain and left-brain functionality. On the other hand, another finding is that there was no difference in whether the pictograms on the right or the left of the package for low-literate participants for product 2 and young participants for product 3. Packages without pictograms reveal that the primary focus is overwhelmingly directed at the center of the packaging, with a secondary focus area towards center-right parts of samples tested. As shown in Figure 6, the logo on the left side is hardly noticed at all.

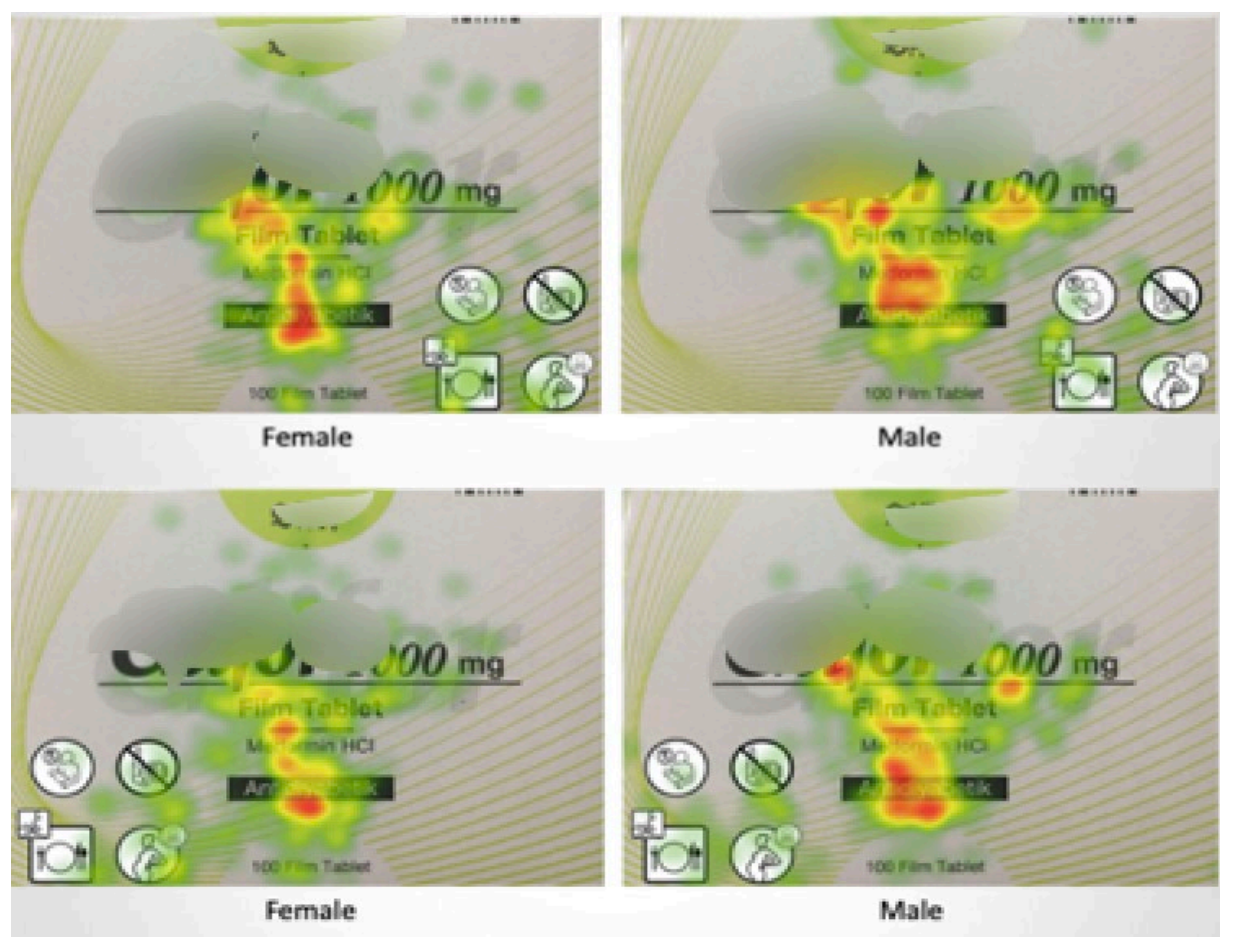

Figure 5. Heatmap with fixation marks of Product 2 (right and left pictograms)

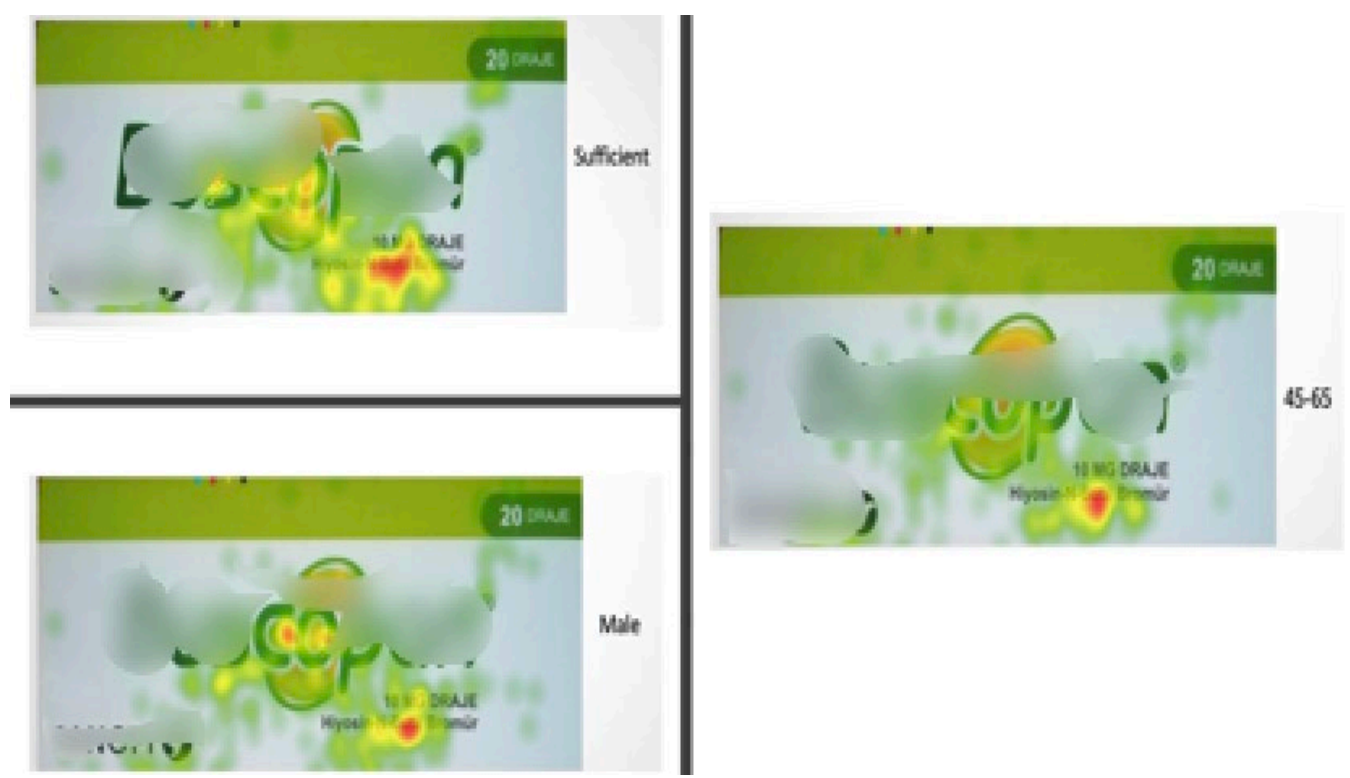

Figure 6. Heatmap with fixation marks of Product 3 without pictograms 
As shown in Table 4, there is a significant correlation between the level of validation of pictograms with the text and the understanding of pictograms.

Table 4. Pearson correlations of variables (2-tailed)

\begin{tabular}{cccccc}
\hline & Health literacy & Agreement Scale & Gender & Age & Comprehension \\
\hline Health literacy & & 0.708 & 0.501 & 0.311 & 0.302 \\
\hline Agreement Scale & 0.708 & & 0.115 & $\mathbf{0 . 0 4 7}^{*}$ & $\mathbf{0 . 0 0 1 * *}$ \\
\hline Gender & 0.501 & 0.115 & & 0.548 & $\mathbf{0 . 0 0 0 * *}$ \\
\hline Age & 0.311 & $\mathbf{0 . 0 4 7} *$ & 0.548 & & 0.248 \\
\hline Comprehension & 0.302 & $\mathbf{0 . 0 0 1 * *}$ & $\mathbf{0 . 0 0 0 * *}$ & 0.248 & \\
\hline
\end{tabular}

$* p<0.05, * * p<0.01$

Another striking result of this study is the significant relationship between the understanding of the pictograms and gender when mean values are examined. Accordingly, it was found that women (mean=54.5788) interpreted pictograms more accurately than men (mean=30.7692).

In this study, no significant relationship was found between health literacy and pictogram comprehension level (Table 4).

\section{DISCUSSION}

In this study, only $13 \%$ of participants achieved the minimum level of comprehension in accordance with ISO 3684. While the results of comprehension the pictograms obtained from the survey are quite low, the results obtained with eye tracking methods provided us with more detailed information and enabled us to obtain more precise results instead of the survey. For this reason, in our study we analyzed participants' responses as well as their visual attention and gaze behavior using eye tracking techniques in addition to the survey.

Our results indicated that noticeability is related to the location of the pictograms. It was found that the eye movement (gaze) of participants changed depending on the position of the visuals. Accordingly, the pictograms were found to be most easily noticed at the center with a secondary focus area towards center-right parts of samples tested. On the other hand, our results clearly showed that the comprehensibility of the pictograms increases when text is available. This result confirms previous research ${ }^{28}$.

The results of fixation times revealed female participants focus more on pictograms than male participants. Regarding the results of female participants, obtained data may be related to women's ability to capture more detailed information. The latter results were also analyzed in studies on facial processing ${ }^{29}$. We also found that women interpreted pictograms more accurately than men. Similarly, elderly participants also focused more on pictograms than young participants. These results may be related to elderly participants' efforts to understand the pictograms.
We can state that pharmaceutical packaging design and placement of related pictograms may be varied by demographic factors - all of which should be considered in developing the packaging strategy. The placement of brand-related visuals such as logo and product name at the center and on the right side of the package, will increase their visibility. For companies, these results are essential in designing product packaging.

We can conclude that participants at least noticed the pictograms, if not immediately, and quickly shifted their attention to other images on the packaging. The percentage fixation for Product 4 which has vertical design is higher than other products (86-95\%) for all demographic characteristics. Vertical design should be preferred because of more engaging.

\section{CONCLUSION}

In our study, it was found that the eye movement (gaze) of participants changed depending on the position of the visuals. Participants focused primarily on visuals that were placed at the center and then visuals that were placed at the center-right parts of the packaging. This result is valid for all types of packaging with or without pictograms and is a remarkable finding for marketing communication.

We observed that participants look from the center to the periphery. Peripheral pictograms were mostly influenced by demographic variables, in contrast to pictograms in the center, which were highly visible in any circumstance. Vertical design is highly engaging for participants regardless of health literacy. Therefore, we recommend that pharmaceutical companies should put critical pictograms near the center of the packaging.

Among the demographic variables, fixation and comprehension of pictograms showed a remarkable difference when the gender of participants is considered. These demographic differences should also be considered in the design of pharmaceutical packaging. 
Pictograms can be made user-friendly by adopting new techniques. Cholewa et al. have shown that augmented reality using a pictogram-based interface is a practical solution for medication adherence ${ }^{30}$. In the near future, the digital transformation of pharmaceutical pictograms will gain importance in patient communication. The adaptation of pictograms using these new technologies merits further scientific examination in future research.

The opinions expressed in this paper are those of the author(s).

Acknowledgements: The authors would like to thank senior pharmacy student Berkay Okursoy who contributed to the pictograms and placed them in the pharmaceutical packages.

Conflict of Interest: The authors declare no conflict of interest. Funding Statement: This research did not receive any specific grant from funding agencies in the public, commercial, or notfor-profit sectors.

\section{REFERENCES}

1. Iuga AO, McGuire MJ. Adherence and health care costs. Risk Manag Healthc Policy. 2014; 7:35. doi: 10.2147/RMHP.S19801.

2. Golay A. Pharmacoeconomic aspects of poor adherence: can better adherence reduce healthcare costs?. J Med Econ. 2011; 14(5): 594608. https://doi.org/10.3111/13696998.2011.597808

3. Leporini C, De Sarro G, Russo E. Adherence to therapy and adverse drug reactions: is there a link?. Expert Opin Drug Saf. 2014;13(1): 41-55. https://doi.org/10.1517/14740338.2014.947260

4. Paivio A, Rogers TB, Smythe PC. Why are pictures easier to recall than words?. Psychon Sci. 1968; 11(4): 137-138. DOI: 10.3758/BF03331011

5. Soares MA. Legibility of USP pictograms by clients of community pharmacies in Portugal. Int. J. Clin. Pharm. 2013; 35(1), 22-29. doi: 10.1007/s11096-012-9698-z.

6. Van Beusekom MM, Kerkhoven AH, Bos MJ, et al. The extent and effects of patient involvement in pictogram design for written drug information: a short systematic review. Drug Discov.

Today 2018; 23(6): 1312-1318. https://doi.org/10.1016/i.drudis.2018.05.013

7. Krueger KP, Berger BA, Felkey B. Medication adherence and persistence: a comprehensive review. Adv Ther. 2005; 22(4): 313-356.

8. Houts PS, Doak CC, Doak LG, et al. The role of pictures in improving health communication: a review of research on attention, comprehension, recall, and adherence. Patient Educ Couns. 2006; 61(2): 173-190. https://doi.org/10.1016/i.pec.2005.05.004
9. Barros IM, Alcântara TS, Mesquita AR, et al. The use of pictograms in the health care: a literature review. Res Social Adm Phar. 2014;10(5): 704719. https://doi.org/10.1016/i.sapharm.2013.11.002

10. Dowse R, Ehlers M. Medicine labels incorporating pictograms: do they influence understanding and adherence?. Patient Educ Couns. 2005; 58(1): 6370. https://doi.org/10.1016/i.pec.2004.06.012

11. Kheir N, Awaisu A, Radoui A, et al. Development and evaluation of pictograms on medication labels for patients with limited literacy skills in a culturally diverse multiethnic population. Res Social Adm Pharm. 2014; 10(5): 720-730. https://doi.org/10.1002/pts.2061

12. Howard DH, Gazmararian J, Parker RM. The impact of low health literacy on the medical costs of Medicare managed care enrollees. Am J Med. 2005; 118(4): 371-377. https://doi.org/10.1016/i.amjmed.2005.01.010

13. Brown MT, Bussell JK. Medication adherence: WHO cares?. In Mayo Clin Proc. 2011; 86(4): 304314. Elsevier.

https://doi.org/10.4065/mcp.2010.0575

14. Mansoor LE, Dowse R. Effect of pictograms on readability of patient information materials. Ann Pharmacoth. 2003; 37(7-8): 1003-1009. https://doi.org/10.1345/aph.1C449

15. Dowse R, Ehlers MS. The influence of education on the interpretation of pharmaceutical pictograms for communicating medicine instructions. Int J Pharm Pract. 2003; 11(1): 1118. https://doi.org/10.1211/002235702810

16. Braich PS, Almeida DR, Hollands S, et al. Effects of pictograms in educating 3 distinct low-literacy populations on the use of postoperative cataract medication. Can J Ophthalmol. 2011; 46(3): 276281. https://doi.org/10.1016/j.jcjo.2011.05.004

17. International Standards Organization (ISO). International standard for safety colours and safety signs: ISO 3864, Switzerland, (1984).

18. Van Beusekom MM, Land-Zandstra AM, Bos MJ, et al. Pharmaceutical pictograms for low-literate patients: understanding, risk of false confidence, and evidence-based design strategies. Patient Educ Couns. 2017; 100(5): 966-973. https://doi.org/10.1016/j.pec.2016.12.015

19. Chan AH, Chan KW. Effects of prospective-user factors and sign design features on guessability of pharmaceutical pictograms. Patient Educ Couns. 2013; 90(2): 268-275. https://doi.org/10.1016/j.pec.2012.10.009

20. Guideline, E. C. Guideline on the Readability of the Labelling and Package Leaflet of Medicinal Products for Human Use, (2009). 
21. Bix L, Bello NM, Auras R, et al. Examining the conspicuousness and prominence of two required warnings on OTC pain relievers. Proc Natl Acad Sci USA. 2009; 106(16): 65506555. https://doi.org/10.1073/pnas.0810665106

22. Montagne M. Pharmaceutical pictograms: a model for development and testing for comprehension and utility. Res Social Adm Pharm. 2013; 9(5): 609-620. https://doi.org/10.1016/j.sapharm.2013.04.003

23. Leong $\mathrm{M}, \mathrm{Tam} \mathrm{V}, \mathrm{Xu} \mathrm{T}$, et al. Understanding medication schedules: do pictograms help?. J Patient Saf. 2018; 14(2): 19-24. doi: 10.1097/PTS.0000000000000241

24. Dowse R, Ehlers MS. Pictograms in pharmacy. Int J Pharm Pract. 1998; 6(2): 109-118.

https://doi.org/10.1111/i.20427174.1998.tb00924.x

25. Van Beusekom M, Bos M, Wolterbeek R, et al. Patients' preferences for visuals: Differences in the preferred level of detail, type of background and type of frame of icons depicting organs between literate and low-literate people. Patient Educ Couns. 2015; 98(2): 226-233. https://doi.org/10.1016/i.pec.2014.10.023
26. Pires C, Vigário M, Cavaco A. Graphical content of medicinal package inserts: an exploratory study to evaluate potential legibility issues. Health Info Libr J. 2016; 33(2): 121-139. https://doi.org/10.1111/hir.12128

27. Ozdemir H, Alper Z, Uncu Y, et al. Health literacy among adults: a study from Turkey. Health Educ Res. 2010; 25(3): 464-477. https://doi.org/10.1093/her/cyp068

28. Katz MG, Kripalani S, Weiss BD. Use of pictorial aids in medication instructions: a review of the literature. Am J Health Syst Pharm. 2006; 63(23): 2391-2397.

https://doi.org/10.2147/RMHP.S19801

29. Heisz JJ, Pottruff MM, Shore DI. Females scan more than males: A potential mechanism for sex differences in recognition memory. Psychol Sci. 2013; 24(7): 1157-1163. https://doi.org/10.1177/0956797612468281

30. Cholewa N, Wołk K, Wołk R. Precise eye-tracking technology in medical communicator prototype. Procedia Comput Sci. 2018; 138: 264-271. https://doi.org/10.1016/j.procs.2018.10.038 